\title{
The human gut bacteria Christensenellaceae are widespread, heritable, and associated with health
}

\author{
Jillian L. Waters and Ruth E. Ley*
}

\begin{abstract}
The Christensenellaceae, a recently described family in the phylum Firmicutes, is emerging as an important player in human health. The relative abundance of Christensenellaceae in the human gut is inversely related to host body mass index (BMI) in different populations and multiple studies, making its relationship with $\mathrm{BMI}$ the most robust and reproducible link between the microbial ecology of the human gut and metabolic disease reported to date. The family is also related to a healthy status in a number of other different disease contexts, including obesity and inflammatory bowel disease. In addition, Christensenellaceae is highly heritable across multiple populations, although specific human genes underlying its heritability have so far been elusive. Further research into the microbial ecology and metabolism of these bacteria should reveal mechanistic underpinnings of their host-health associations and enable their development as therapeutics.
\end{abstract}

\section{Introduction}

The composition of the human gut microbiome is now well established as a factor important to human health conditions, including metabolic, pathogen, and immunerelated diseases [1]. Its composition varies substantially between individuals and populations due to local, personal, and stochastic factors. The high inter-individual variability of the gut microbiome has challenged efforts to define what constitutes a healthy versus an unhealthy microbiome. Indeed, community composition alone is generally not a good predictor of disease state [2]. The contribution

\footnotetext{
* Correspondence: ruth.ley@tuebingen.mpg.de

Department of Microbiome Science, Max Planck Institute for Developmental Biology, Max-Planck-Ring 5, 72076 Tuebingen, Germany
}

of specific taxa, their metabolic pathways, and their interactions to human health is a new priority for microbiome research [3], and this deeper understanding of the microbiome will be necessary for the development of evidencebased microbial therapeutics [4-6]. Given that thousands of microbial species and strains live in the gut, one challenge is to identify targets for further investigation and development.

Here, we focus on the family Christensenellaceae, within the Firmicutes phylum of Bacteria, due to its emergence as a health-related group. First encountered from $16 \mathrm{~S}$ rRNA gene sequences alone, the family was named in 2012 after an isolate named Christensenella minuta (pictured in Fig. 1), cultivated from the feces of a healthy Japanese male [7]. Members of this family of Firmicutes are, with a few exceptions, increasingly revealing themselves as associated with a healthy phenotype in humans. Because of the relatively recent naming and phylogenetic placement of the Christensenellaceae family (Box 1), it was not discussed in the literature prior to a few years ago. And since representatives of this family were only recently isolated (Box 2), little is known about its ecology outside of what can be inferred from its associations with host factors and other microbiota (Box 3). Here, we review the literature to date, focusing on consistent trends that associate Christensenellaceae with parameters of human health. Taken together, these various observations strongly argue for further investigation into the Christensenellaceae.

\section{Christensenellaceae is ubiquitous among humans and other animals}

Most of what is known about the family Christensenellaceae comes from 16S rRNA gene surveys of the microbiome obtained from feces of humans and other animals. Given that Christensenellaceae 16S rRNA gene sequences were relatively recently included in reference databases, only microbiome studies published since 2013

(c) The Author(s). 2019 Open Access This article is distributed under the terms of the Creative Commons Attribution 4.0 International License (http://creativecommons.org/licenses/by/4.0/), which permits unrestricted use, distribution, and 


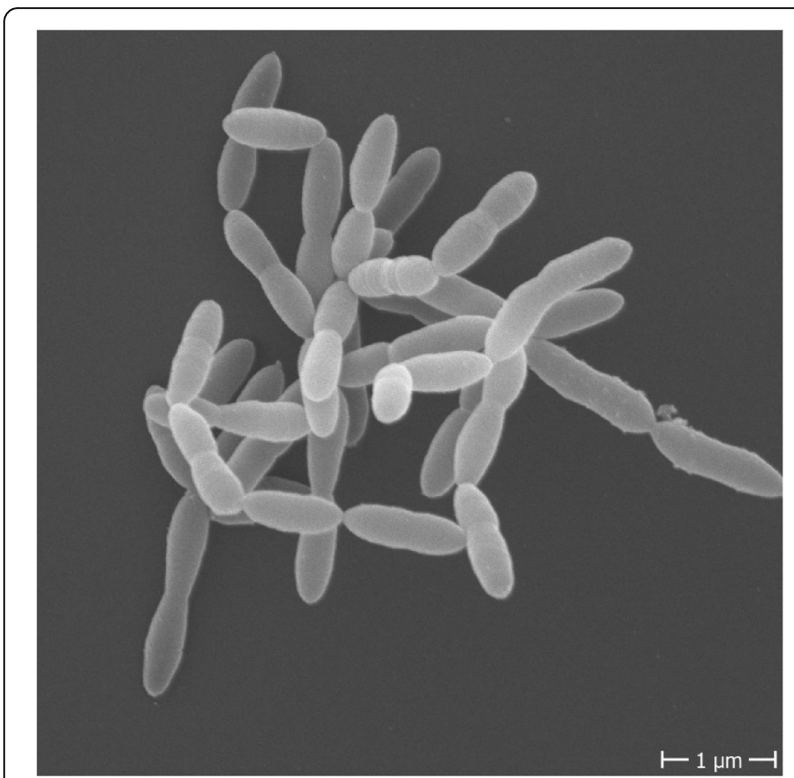

Fig. 1 Cell morphology of Christensenella minuta. C. minuta (DSM22607) was grown in supplemented brain heart infusion to reach full turbidity, approximately $72 \mathrm{~h}$. Cells were washed twice and subsequently resuspended in phosphate buffered saline prior to submission to the electron microscopy facility at the Max Planck Institute for Developmental Biology

Box 1 Discovery and phylogenetic classification of the Christensenellaceae

The family Christensenellaceae belongs to the bacterial phylum Firmicutes, the phylogenetically diverse and predominant phylum of the human gut microbiome. The name Christensenellaceae is derived from the isolate named Christensenella minuta (pictured in Fig. 1), which was first cultivated from the feces of a healthy Japanese male by Morotomi and colleagues and published in 2012 [7]. This isolate was named to honor the Danish microbiologist Henrik Christensen, and the species designated "minuta", due to the small size of the cell $(0.8-1.9 \mu \mathrm{M})$ and the colonies it forms on agar plates (only $0.1 \mathrm{~mm}$ in diameter). In their species description,

Morotomi et al. compared C. minuta's full length 16S rRNA against publicly available databases and identified Caldicoprobacter oshimai, a bacterium in the family Caldicoprobactereaceae (Clostridiales), as the closest relative, with 86.9\% pairwise ID. Other related taxa included Tindallia californiensis (86.3\% ID) and Clostridium ganghwense ( $86.1 \%$ ID), both of which are in the family Clostridiaceae in the phylum Firmicutes. They did note that other sequences were identified with matches greater than 98\% ID; however, these were unclassified taxa from other $16 \mathrm{~S}$ rRNA gene diversity surveys. $C$. minuta was designated to represent a novel family, Christensenellaceae, in the order Clostridiales in the phylum Firmicutes [7].

A closely related bacterium, Catabacter hongkongensis, was described in 2007 [8]. The 16S rRNA genes of C. minuta and Catabacter hongkongensis share $96.5 \%$ sequence identity, suggesting the two should be in the same family, and possibly the same genus [9] (Fig. 2). As a result, some databases use the family name Catabacteriaceae, some use Christensenellaceae, and some studies include both as two distinct families. The family name Christensenellaceae, however, is now considered with standing in nomenclature [10]. The Genome Taxonomy Database, a recent taxonomy developed by Phil Hugenholtz and colleagues that is based on whole genome comparisons rather than 165 rRNA gene sequences for reconstructing phylogeny, supports that Christensenella and Catabacter are separate genera in the family Christensenellaceae, within a new order Christensenellales [11].
Box 2 Cultured isolates of the family Christensenellaceae (2019)

The first isolate, Christensenella minuta (DSM 22607), was isolated from the feces of a healthy Japanese male. It is strictly anaerobic, nonsporulating, non-motile, and described as Gram-negative [7]. Intriguingly, others have described it as Gram-positive [12], which is also consistent with our unpublished observations. A Gram-positive cell wall is consistent with its classification as belonging to the phylum Firmicutes, which includes predominantly Gram-positive bacteria. However, C. minuta is able to produce small amounts of lipopolysaccharide, an attribute that is more typical of, but not exclusive to, Gram-negative bacteria [13]. Morotomi and colleagues demonstrated that C. minuta produces the short chain fatty acids acetate and butyrate, and is saccharolytic, with the ability to utilize arabinose, glucose, mannose, rhamnose, salicin, and xylose. C. minuta was negative for many of the standard biochemical assays used for characterization, which included catalase, oxidase, esculin and gelatin hydrolysis, indole production, and nitrate reduction [7]. The genome was published in 2017 [14], and is estimated as $2.94 \mathrm{Mb}$ with $51.5 \% \mathrm{G}+\mathrm{C}$ content.

Catabacter hongkongensis (DSM 18959), first described in 2007, was isolated from the blood of patients who developed bacteremia in Canada and Hong Kong. Catabacter hongkongensis is described as strictly anaerobic, non-sporulating, and Gram-positive [8]. In contrast to the other Christensenella isolates, Catabacter hongkongensis is in fact motile. Catabacter has been associated with bacteremia in at least 12 additional instances, and there may be more due to the difficulty in many chemical-based methods of accurately identifying Catabacter hongkongensis [15-17]. Catabacter hongkongensis has a similar saccharolytic profile to C. minuta, with the exception of glycerol and rhamnose utilization depending on the isolate, and it was not able to utilize salicin. Catabacter hongkongensis differs from C. minuta in that it is catalase positive. Like C. minuta, it was negative for oxidase, esculin and gelatin hydrolysis, indole production, and nitrate reduction [8]. No short chain fatty acid production has been reported for Catabacter. The genome for this bacterium was published in 2015 , and is $3.2 \mathrm{Mb}$ with $48.5 \% \mathrm{G}+\mathrm{C}$ content. Annotation of the genome supported that Catabacter hongkongensis is motile, and the authors identified a number of antibiotic resistance genes, which may contribute to its pathogenicity [18].

Christensenella massiliensis (DSM 102344) and Christensenella timonensis (DSM 102800), both isolated from the feces of a diabetic patient in Marseilles, France, are described as strictly anaerobic, non-motile, non-sporulating, and Gram-negative, similar to C. minuta $[19,20]$. Although 165 rRNA gene sequence comparisons place $C$. timonensis within the Christensenella genus (> 97\% identity to C. minuta), whole genome taxonomy indicates it belongs to a genus distinct from both Christensenella and Catabacter [11]. No characterization of these isolates has been reported.

report this taxon. Two cultured isolates, Christensenella minuta and Catabacter hongkongensis, have published genomes $[14,18]$, and genomes constructed during metagenomic assemblies are increasingly available. At the time of writing this review, there are 11 Christensenellaceae genomes in the Genome Taxonomy Database and 89 genomes for the order Christensenellales (Box 1) [11]. A phylogeny of 9 members of the Christensenellaceae, based on full length $16 \mathrm{~S}$ rRNA gene sequences available in NCBI, is shown in Fig. 2. Surveying the post2013 literature, it is evident that members of the Christensenellaceae are cosmopolitan inhabitants of the animal gut (Table 1), with a likely preference for the distal colon [44], which is consistent with its fermentative activities (detailed in Box 3) [7].

In humans, the family comprises on average $0.01 \%$ of the fecal microbiota [21]. Its fine-scale distribution along 
Box 3 Ecological role of the Christensenellaceae in the human gut Based on Morotomi's observations, C. minuta ferments glucose to acetate and butyrate under anaerobic conditions [7], which indicates it ferments sugars in the gut to short chain fatty acids and other fermentation products such as $\mathrm{H}_{2}$ and $\mathrm{CO}_{2}$. Goodrich et al. reported that the Christensenellaceae form the hub of a co-occurrence network with other microbiota, including methanogens (archaea of the family Methanobacteriaceae) [21]. Co-occurrence of Christensenellaceae and Methanobacteriaceae across individuals has been reported elsewhere [22, 23]. The Methanobacteriaceae include Methanobrevibacter smithii, the predominant methanogen in the human gut. Given that M. smithii uses fermentation products (e.g., $\mathrm{H}_{2}$ and $\mathrm{CO}_{2}$ ) to produce methane, the co-occurrence with Christensenellaceae may represent a $\mathrm{H}_{2}$-based syntrophy.

the human gastrointestinal tract remains to be clarified; but in addition to feces, Christensenellaceae has been detected in human colonic mucosa, ileum, and appendix, and there is also suggestive evidence of airway colonization [21, 56-59]. The family Christensenellaceae is widespread across human populations, and is reported from subjects inhabiting North America [60-62], South America [63, 64], Europe [21, 65], Asia [66, 67], Africa [68-70], and Australia [71].

Within human populations, traits associated with different relative abundances of Christensenellaceae include ethnicity and sex. For instance, a recent study of $>2000$ individuals with various ethnicities residing in Amsterdam, Deschasaux et al. reported that Dutch subjects harbored the greatest relative abundances of Christensenellaceae [72]. Similarly, Brooks et al. compared microbiome variation between ethnicities in 1673 people residing in the USA and reported that Christensenellaceae was overall less represented in fecal samples of Asian-Pacific Islanders relative to other ethnicities [60]. A greater relative abundance of Christensenellaceae in women compared to men was also observed [60], and similar observations have been reported in animals $[26,73,74]$. The underlying causes of these ethnic and sex differences are unclear.

Christensenellaceae has been associated with human longevity, based on the observation that the relative abundance of Christensenellaceae is greater in centenarians and supercentenarians in comparison to younger individuals in populations in China [75, 76], Italy [77], and Korea [78]. Positive associations of Christensenellaceae with age have also emerged from studies with relatively young individuals across multiple geographic locations [60, 68, 7982] (Table 2). Given that none of these studies followed the same individuals over time, the association with age could reflect a cohort effect rather than an age effect. For

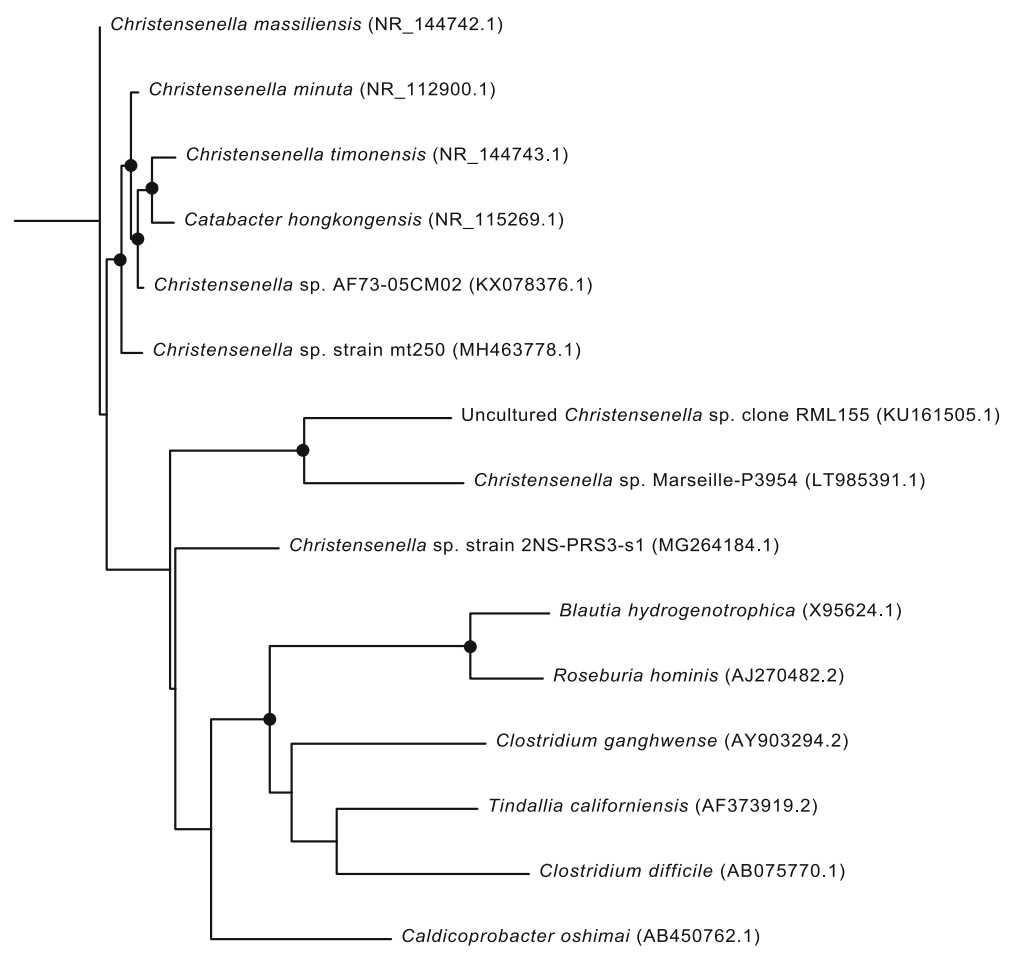

0.08

Fig. 2 Phylogenetic relatedness of Christensenellaceae. Full length 16S rRNA gene sequences were obtained from NCBI and aligned using MAFFT. Accession numbers for each sequence are provided in parentheses. Bootstrap values (> 50\%) are expressed as a percentage for 100 iterations. A maximum likelihood tree was built using RaxML with a general time reversible evolutionary model, and B. thetaiotaomicron was selected as the outgroup for rooting the tree. The scale bar represents substitutions per site 
Table 1 Christensenellaceae has a wide range of hosts in the animal kingdom

\begin{tabular}{|c|c|c|c|c|c|c|c|}
\hline Phylum & Class & Order & Family & Genus & Species & Common name & References \\
\hline \multirow[t]{36}{*}{ Chordata } & \multirow[t]{4}{*}{ Aves } & Casuariiformes & Casuariidae & Dromaius & novaehollandiae & Emu & [24] \\
\hline & & \multirow[t]{2}{*}{ Galliformes } & \multirow[t]{2}{*}{ Phasianidae } & Gallus & gallus & Chicken & {$[25]$} \\
\hline & & & & Coturnix & japonica & Japanese quail & {$[26]$} \\
\hline & & Struthioniformes & Struthionidae & Struthio & camelus & Ostrich & {$[27]$} \\
\hline & \multirow[t]{28}{*}{ Mammalia } & \multirow[t]{11}{*}{ Artiodactyla } & \multirow[t]{5}{*}{ Bovidae } & \multirow[t]{2}{*}{ Bos } & frontalis & Gayal & {$[28]$} \\
\hline & & & & & taurus & Cow & {$[28,29]$} \\
\hline & & & & Capra & aegagrus hircus & Goat & {$[30]$} \\
\hline & & & & Syncerus & caffer & African Buffalo & {$[28]$} \\
\hline & & & & Ovis & aries & Sheep & [31] \\
\hline & & & \multirow[t]{2}{*}{ Camelidae } & \multirow[t]{2}{*}{ Camelus } & bactrianus & Bactrian camel & {$[32]$} \\
\hline & & & & & dromedarius & Dromedary camel & {$[33]$} \\
\hline & & & \multirow[t]{2}{*}{ Cervidae } & \multirow[t]{2}{*}{ Cervus } & nippon & Sika Deer & [34] \\
\hline & & & & & elaphus & Red deer & {$[28]$} \\
\hline & & & Giraffidae & Giraffa & camelopardalis & Giraffe & {$[28]$} \\
\hline & & & Suidae & Sus & scrofa & Pig & {$[35,36]$} \\
\hline & & \multirow[t]{2}{*}{ Carnivora } & Canidae & Canis & lupus & Dog & {$[37]$} \\
\hline & & & Felidae & Felis & catus & Cat & {$[38]$} \\
\hline & & Diprotodontia & Vombatidae & Lasiorhinus & latifrons & Southern hairy-nosed wombat & {$[39]$} \\
\hline & & Lagomorpha & Leporidae & Oryctolagus & cuniculus & Rex rabbit & {$[40]$} \\
\hline & & \multirow[t]{2}{*}{ Perissodactyla } & \multirow[t]{2}{*}{ Equida } & Equus & caballus & Horse & {$[28,41]$} \\
\hline & & & & Equus & quagga & Zebra & {$[28]$} \\
\hline & & \multirow[t]{5}{*}{ Primates } & \multirow[t]{5}{*}{ Cercopithecidae } & \multirow[t]{3}{*}{ Cercopithecus } & ascanius $^{a}$ & Red-tailed monkey & {$[42]$} \\
\hline & & & & & wolfia & Wolf's mona monkey & {$[42]$} \\
\hline & & & & & neglectus $^{a}$ & De Brazza's monkey & {$[42]$} \\
\hline & & & & Macaca & mulatta & Rhesus Macaque & [43] \\
\hline & & & & papio & anubis & Baboon & {$[44]$} \\
\hline & & \multirow[t]{4}{*}{ Rodentia } & \multirow[t]{2}{*}{ Cricetidae } & Cricetus & cricetus & European hamster & [28] \\
\hline & & & & Microtus & californicus scirpensis & Amargosa vole & {$[45]$} \\
\hline & & & \multirow[t]{2}{*}{ Muridae } & Mus & musculus & Mouse & {$[46]$} \\
\hline & & & & Rattus & norvegicus & Rat & {$[47]$} \\
\hline & & \multirow[t]{2}{*}{ Sirenia } & Dugongidae & Dugong & dugon & Dugong & {$[48]$} \\
\hline & & & Trichechidae & Trichechus & Manatus manatus & Antillean manatee & [49] \\
\hline & \multirow[t]{4}{*}{ Reptilia } & \multirow[t]{3}{*}{ Squamata } & Lacertidae & Podarcis & lilfordi & Lilford's wall lizard & {$[50]$} \\
\hline & & & \multirow[t]{2}{*}{ Liolaemidae } & Liolaemus & parvus & Lesser smooth-throated lizard & [51] \\
\hline & & & & & ruibali & Ruibal's tree iguana & {$[51]$} \\
\hline & & Testudines & Testudinidae & Gopherus & polyphemus & Gopher tortoise & {$[52]$} \\
\hline Anthropoda & Insecta & Coleoptera & Scarabaeidae & Holotrichia & parallela & Large black chafer & [53] \\
\hline & & Blattodea & Blaberidae & Diploptera & punctata & Pacific beetle cockroach & {$[54]$} \\
\hline & & & & Pycnoscelus & surinamensis & Surinam cockroach & {$[55]$} \\
\hline
\end{tabular}

${ }^{a}$ Christensenellaceae is listed as detected in the Cercopithecus genus, without further species detail. The three species listed were studied in McKenzie et al. [42]

example, dietary patterns that vary by age may influence this association (see below), or individuals born earlier may have always harbored greater levels of Christensenellaceae compared to those born later.
The Christensenellaceae are linked to host genetic variation

Host genotype is estimated to influence $30-60 \%$ of the variation in the relative abundance of Christensenellaceae 
Table 2 The relative abundance of Christensenellaceae increases with age

\begin{tabular}{|c|c|c|c|c|}
\hline \multirow[t]{2}{*}{ Country } & \multirow{2}{*}{$\begin{array}{l}\text { Sample size } \\
\text { of cohort }\end{array}$} & \multirow{2}{*}{$\begin{array}{l}\text { Age } \\
(\text { mean } \pm \text { std. dev. })^{*, \#}\end{array}$} & Sex & \multirow[t]{2}{*}{ Reference } \\
\hline & & & (\% male/\% female) & \\
\hline \multirow[t]{2}{*}{ China } & \multirow[t]{2}{*}{168} & 93.3 (90-102) Long-living people ${ }^{\#}$ & $37 / 63$ & \multirow[t]{2}{*}{ [75] } \\
\hline & & $61.6(24-83)$ Young $^{\#}$ & $52 / 48$ & \\
\hline \multirow[t]{3}{*}{ China } & \multirow[t]{3}{*}{24} & 104 (100-108) Centenarians* & $38 / 62$ & \multirow[t]{3}{*}{ [76] } \\
\hline & & 92 (85-89) Bama elderly* & $38 / 62$ & \\
\hline & & 83 (80-92) Nanning elderly* & $50 / 50$ & \\
\hline \multirow[t]{4}{*}{ Italy } & \multirow[t]{4}{*}{69} & 106.2 (105-109) Semi-supercentenarians ${ }^{\#}$ & $25 / 75$ & \multirow[t]{4}{*}{ [77] } \\
\hline & & 100.4 (99-104) Centenarians ${ }^{\#}$ & $7 / 93$ & \\
\hline & & 72.5 (65-75) Elderly ${ }^{\#}$ & $47 / 53$ & \\
\hline & & 30.5 (22-48) Adults ${ }^{\#}$ & $47 / 53$ & \\
\hline \multirow[t]{3}{*}{ Korea } & \multirow[t]{3}{*}{47} & $98.9 \pm 3.4$ Centenarians & 33,147 & \multirow[t]{3}{*}{ [78] } \\
\hline & & $73.6 \pm 3.6$ Elderly & $59 / 41$ & \\
\hline & & $34.3 \pm 6.5$ Adults & $67 / 33$ & \\
\hline Korea & 57 & 25-65 (no other participant info or table) & $54 / 46$ & [82] \\
\hline USA & 1673 & $40.2 \pm 9.7^{\mathrm{a}}$ & $52 / 48^{\mathrm{a}}$ & [60] \\
\hline USA & 28 & $49.5(20-82)^{*}$ & $54 / 46$ & [79] \\
\hline Nigeria & $30^{\mathrm{b}}$ & Infant- $85^{c}$ & NA & [68] \\
\hline United Kingdom & $2764^{d}$ & $59.5 \pm 12.3$ & 32,813 & [81] \\
\hline Canada & 41 & $24.3 \pm 3.7^{e}$ & $54 / 46$ & [80] \\
\hline
\end{tabular}

* In these studies age is reported as median (age range)

\# In these studies age is reported as average (age range)

a Metadata were only reported for the American Gut Participants $(n=1375)$ as participant data for the Human Microbiome Project is restricted access

b These findings only pertain to the urban dwelling Nigerians from this study

${ }^{c}$ A median or average for age groups was not provided. Infants were defined as $<3$ years of age $(n=12)$ and adults were $5-85(n=18)$

d These values only pertain to the analysis in the TwinsUK cohort in this paper

e These values are reported for the AVG cohort with regard to cardiorespiratory fitness, but is reflective of all study participants. Total age range for all participants is between 18 and 35 years

across individuals $[21,62,66,83]$. Of the hundreds of taxa in the gut, the family Christensenellaceae is consistently identified as among the most highly heritable. This means that a significant proportion of the variance in the relative abundance of the family across a population can be attributed to genetic factors. Heritability refers to the genetic predisposition of a quantitative trait: for example, height is heritable, because this trait is largely genetically determined. Heritability calculations take into account quantitative measures of the trait (such as relative abundance) and should not be confused with whether the Christensenellaceae are inherited (i.e., vertically transmitted) from family members, which is not known.

Goodrich et al. first identified the Christensenellaceae as heritable in a well-powered $(n=977)$ study of monozygotic and dizygotic twins from the UK [21]. A remarkable $40 \%$ of the variation between individuals in the relative abundance of the family Christensenellaceae could be attributed to host genetic factors. A more finegrained analysis of species-level operational taxonomic units (OTUs) showed that just a few Christensenellaceae OTUs were driving the heritability of the family [21]. Other studies of heritability employing the same population have observed similar results, whether the analysis was specific to species-level OTUs or when analyzing modules of co-occurring microbes [81, 84]. So far, the Christensenellaceae have not been included in the analysis of heritability based on shotgun metagenome data, due to the absence of genomes for this family in the reference databases used [85].

The high heritability of the Christensenellaceae has been corroborated in other human populations. Goodrich et al. had confirmed its heritability in two previous studies involving twin pairs from the USA [21, 61, 86]. Additionally, Lim et al. evaluated microbiome heritability in a Korean cohort of 655 individuals and identified Christensenellaceae as heritable. In a Canadian cohort $(n=270)$, it was again identified as among the most highly heritable taxa [62]. Together, these observations across multiple populations indicate that the heritability of the Christensenellaceae is a widely shared trait. That individuals are genetically predisposed to harbor a high or low relative abundance of these bacteria may be a generalizable human trait.

So far, attempts to identify the genetic factors that account for the high heritability of Christensenellaceae by 
genome-wide association (GWA) have not succeeded [83]. These studies are generally underpowered, given the millions of tests conducted simultaneously (i.e., testing all genetic variants against all microbiome traits), and the necessity to correct for false positives [87]. An alternative to GWA is to take a candidate gene approach, restricting the analysis to genes with interesting functions. For instance, Zakrzewski et al. examined the relationship between a SNP in the interleukin 23 receptor (ILR23) gene and the microbiome of mucosal biopsies from the ileum and rectum. The A allele of this variant has been associated with a reduced risk of ileal Crohn's disease (CD). Within a population of individuals with no signs of $C D$ or other gastrointestinal disorders, a significantly greater relative abundance of Christensenellaceae was detected in the feces of individuals harboring the protective allele (AG genotype) compared to the population with the GG genotype [56]. How the IL23R genotype may affect members of the gut microbiota remains to be clarified.

Christensenellaceae has also been associated with the fucosyltransferase 2 (FUT2) gene, which encodes an enzyme responsible for $\mathrm{ABO}$ blood group antigens that are expressed on the intestinal surface as well as secreted. Nonsecretors (AA genotype) have an elevated risk for $\mathrm{CD}$, while secretors (AG or GG) are less likely to develop CD [88]. A re-analysis of healthy individuals studied in [88] showed that secretors harbored relatively more of this family compared to non-secretors $(n=24)$ [21]. It is important to note that in this case a targeted approach was used, and subsequent studies associating the microbiome with FUT2 do not reach this same conclusion. When Davenport et al. also did this analysis in UK twins $(n=1503)$, where heritability of Christensenellaceae was first reported, no link between Christensenellaceae and secretor status was found [89], which is consistent with the results of Turpin et al. in a cohort of 1190 healthy individuals [90].

The Christensenellaceae may interact with host genetic status to affect risk of colorectal cancer (CRC). Le Gall et al. reported elevated Christensenellaceae in healthy controls relative to individuals with CRC $(n=50$ ageand sex-matched individuals per group) [91], yet Yazici et al. observed that the relative abundance of Christensenellaceae in stool was higher on average in AfricanAmerican CRC patients compared to controls [92]. Furthermore, using tumor and healthy mucosal tissue biopsies from 44 patients with five different loss-of-function mutations in CRC, Burns et al. observed that the association of Christensenellaceae with CRC was dependent on the type of mutation present [58]. These findings may offer an explanation for the inconsistent patterns of Christensenellaceae abundance with respect to CRC status. However, whether the Christensenellaceae participate in CRC pathology remains to be ascertained. While associations between Christensenellaceae and host genotypes remain to be reproduced, they suggest that health/disease promotion by these genotypes may be mediated in part through promotion of the Christensenellaceae.

\section{The Christensenellaceae are linked to metabolic health}

\section{Body composition and metabolic health}

Body mass index (BMI) was the first host phenotype associated with the relative abundance of Christensenellaceae in the gut. Goodrich et al. observed that Christensenellaceae was significantly enriched in individuals with a normal BMI (18.5-24.9) compared to obese individuals $(\mathrm{BMI} \geq 30)$ [21]. Since this initial observation, the association of Christensenellaceae with a normal BMI has been corroborated repeatedly in populations from a number of countries that included adult men and women of various ages (Table 3). Consistent with its association with leanness, Christensenellaceae have been shown to increase after diet-induced weight loss [100]. Although obese and lean subjects can often be differentiated using aspects of microbial ecology of the gut, these aspects (e.g., alpha-diversity, or abundances of phyla) have differed between studies [101]: the link between Christensenellaceae and BMI therefore stands as the strongest corroborated association between the gut microbiome and BMI.

BMI is a proxy for adiposity, and consistent with reports linking levels of Christensenellaceae with BMI, studies in which adiposity is more directly measured have also noted strong associations with the abundance of Christensenellaceae in the gut. For instance, Beaumont et al. correlated adiposity measures, determined using dual $\mathrm{x}$-ray absorptiometry (DEXA), with the microbiome in a study of 1313 UK twins. At the family level, the most significant association was with Christensenellaceae, which negatively correlated with visceral fat mass [84], a type of fat that is considered a cardiometabolic risk factor. A similar observation was made by Hibberd et al., who reported significant negative correlations of Christensenellaceae with trunk fat and android fat [102]. Additionally, Christensenellaceae has been negatively correlated with waist circumference and waist to hip ratio, which are direct markers of central adiposity [66, 102-104].

In addition to its association with body fat measures, Christensenellaceae is negatively correlated with serum lipids in several studies. In the Dutch LifeLines DEEP cohort $(n=893)$, Fu et al. reported a negative correlation of Christensenellaceae with BMI, together with a strong association with low triglyceride levels and elevated levels of high density lipoprotein (HDL, or "good cholesterol") [96]. Other groups have also reported that Christensenellaceae is associated with reduced serum triglycerides [66, 102, 104]. Similarly, this family is also negatively associated with total cholesterol, low density 
Table 3 Global associations of Christensenellaceae with a healthy body mass index

\begin{tabular}{|c|c|c|c|c|}
\hline Country & Sample size of cohort & Age (mean \pm std. dev.)* & Sex (\% male/\% female) & Reference \\
\hline$\overline{U S A}$ & 154 & $15(21-32)^{*, a}$ & $0 / 100$ & {$[61]$} \\
\hline USA & 599 & $62.7 \pm 7.7^{b}$ & $54 / 46$ & [93] \\
\hline USA & 1673 & $40.2 \pm 9.7^{c}$ & $52 / 48^{c}$ & {$[60]$} \\
\hline Mexico & 138 & $9.9 \pm 1.72^{b}$ & $58 / 42$ & [94] \\
\hline United Kingdom & 977 & $60.6 \pm 0.3$ & $2 / 98$ & [21] \\
\hline United Kingdom & $2764^{d}$ & $59.5 \pm 12.3$ & $11 / 89$ & [81] \\
\hline Spain & 39 & $14.8(13-16)^{*}$ & $49 / 51$ & [95] \\
\hline Netherlands & 893 & $44.7 \pm 12.9$ & $43 / 57$ & [96] \\
\hline Norway & 384 & $48(23-82)^{*}$ & $42 / 58$ & [97] \\
\hline Norway & 169 & $30(27-34)^{*}$ & $0 / 100$ & [98] \\
\hline Korea & 655 & $47.0 \pm 12.2$ & $42 / 58$ & [66] \\
\hline Korea & 1274 & $45.7 \pm 9.0$ & $64 / 36$ & [99] \\
\hline Japan & 516 & $52.4 \pm 13.4$ & $37 / 63$ & {$[67]$} \\
\hline
\end{tabular}

* In these studies age is reported as median (range)

a 49 participants are mothers of the twins, for which no age is reported

${ }^{b}$ These values are reported for the healthy weight cohort, but is reflective of all study participants

${ }^{c}$ Metadata were only reported for the American Gut Participants $(n=1375)$ as participant data for the Human Microbiome Project is restricted access

${ }^{d}$ These values only pertain to the analysis in the TwinsUK cohort in this paper. Other studies were included, but Christensenellaceae was not reported

lipoprotein (LDL; or "bad cholesterol"), and apolipoprotein B, a component of LDL particles [94, 102].

Christensenellaceae is reported as depleted in individuals with metabolic syndrome (MetS) compared to healthy controls $[66,104]$. In addition to excess visceral fat, MetS includes other risk factors such as dyslipidemia and impaired glucose metabolism, and is a risk factor for type 2 diabetes and cardiovascular disease. Christensenellaceae was identified in a cohort of 441 Colombians as positively associated with a lower cardiometabolic risk score [103], and others report it is negatively correlated with blood pressure $[66,104,105]$, which is often elevated in MetS [106]. Christensenellaceae has also been associated with healthy glucose metabolism [66, 107] and Christensenellaceae OTUs are reduced in individuals with pre-type 2 diabetes [65]. Given that a high BMI, impaired glucose metabolism, dyslipidemia, and other aspects of MetS are comorbidities, it is not surprising that Christensenellaceae inversely tracks with many of these conditions. The mechanism underlying its negative association with MetS remains to be elucidated.

Metabolic disorders are often linked to dietary patterns. The Christensenellaceae appear to be responsive to diet, and evidence points to a role in protein and fiber fermentation. On a coarse level, large-scale diet studies have associated Christensenellaceae with healthy dietary habits low in refined sugar and high in consumption of fruit and vegetables [108-110]. Christensenellaceae is reported higher in relative abundance in humans with an omnivorous diet, relative to vegetarians $[71,111]$, and has also been associated with dairy consumption [112]. In a more direct link,
Christensenellaceae has been shown to respond rapidly to an increase in animal products in the diet [113]. Furthermore, Christensenellaceae has been positively associated with gut metabolites typical of protein catabolism and dietary animal protein [114-116]. Christensenellaceae has also been reported to increase in human dietary interventions involving prebiotic fibers such as resistant starch 4 , galacto-oligosaccharide, and polydextrose [22, 102, 112]. Similar observations have also been made in rodent models [117-119]. Taken together, these studies indicate that the association of Christensenellaceae with health parameters may in part be due to its association with a diet high in protein and fiber.

To test for a causal role for Christensenellaceae in metabolic disease while controlling for diet, Goodrich et al. selected an obese human donor based on almost undetectable levels of Christensenellaceae in the microbiome, and performed fecal transfers to germfree mice that were fed the same fiber-rich chow, but otherwise only differed by whether or not the obese human microbiome inoculum was amended with $C$. minuta. These experiments showed that amendment with $C$. minuta reduced the adiposity gains of mice compared to those that received unamended stool (or stool amended with heat-killed C. minuta) [21]. The mechanism underlying the protective effect of $C$. minuta against excess adiposity gain remains to be elucidated, but may involve remodeling the microbial community, as a shift in diversity was observed when $C$. minuta was added. These experiments demonstrated that the activity of $C$. minuta in the gut microbiome can affect host body composition even when diet is controlled for, possibly via interactions with 
other members of the microbiota. Indeed, the ecological role of members of the Christensenellaceae and their function in the gut in general remains to be better understood (Box 3).

\section{Inflammation and transit time}

In a meta-analysis of inflammatory bowel disease (IBD) that included over 3000 individuals, Mancabelli et al. reported Christensenellaceae as one of five taxa considered a signature of a healthy gut [120]. Indeed, Christensenellaceae were consistently depleted in individuals with Crohn's disease [121-129] and ulcerative colitis [97, 122, $125,129,130]$, the two major sub-types of IBD. In irritable bowel syndrome (IBS), a gastrointestinal disorder characterized by abdominal pain and abnormal bowel movements, a higher relative abundance of Christensenellaceae in healthy controls relative to individuals with IBS has been reported in several studies [131-134]. Several studies have also noted a positive correlation of Christensenellaceae and longer transit time or even constipation $[67,114,133,135,136]$. Thus, the Christensenellaceae appear to be depleted in conditions associated with inflammation and fast transit time.

Given Christensenellaceae's link with transit time, it is perhaps not surprising that the family has been linked to affective disorders that impact gut motility. For instance, gastric dysfunction, particularly constipation, affects approximately two-thirds of patients with Parkinson's disease (PD) and multiple sclerosis (MS) [137, 138]. Studies have noted a greater relative abundance of Christensenellaceae in PD and MS patients relative to healthy controls [139-142]. Since diet is also related to gut transit time, the effects of diet, host status, and host genetics remain to be carefully disentangled to better understand how levels of the Christensenellaceae are controlled.

\section{Prospectus}

The family Christensenellaceae is a relatively recently described bacterial family that is highly heritable and shows compelling associations with host health. Its strong ties to host health have warranted the suggestion that cultured representatives of the Christensenellaceae, such as C. minuta, should be considered for use as a therapeutic probiotic for the improvement of human health [143]. However, the functional role of Christensenellaceae in the gut remains to be understood. While the collection of associations between Christensenellaceae and host health parameters continues to grow, allowing inferences about the role of these bacteria, they remain to be studied experimentally. Genomes offer a powerful platform for generating hypotheses regarding the metabolic capacity of the Christensenellaceae, but further functional characterization in vitro and in vivo will be necessary to fully characterize the role of
Christensenellaceae in the gut. The ecological role of members of the Christensenellaceae, their interactions with other members of the microbiome and with the host and host diet, all remain to be better understood if these intriguing microbes are to be harnessed fully to improve human health.

\section{Acknowledgements}

We thank Tanja Schoen, Taichi Suzuki, Nicholas Youngblut, and Tony Walters for input on earlier drafts of this manuscript, in addition to the edits and suggestions from two anonymous reviewers. Funding was provided by the Max Planck Society.

\section{Authors' contributions}

JLW and REL wrote this article and read and approved the final version.

\section{Availability of data and materials}

16S rRNA gene sequences used to construct the phylogenetic tree were obtained from NCBI (https://www.ncbi.nlm.nih.gov/). Accession numbers for each sequence are in parentheses in Fig. 2.

\section{Competing interests}

R.E.L. and J.L.W. are co-inventors on patent number US10206958B2, "Modulation of fat storage in a subject by altering population levels of christensenellaceae in the Gl tract".

Received: 16 September 2019 Accepted: 17 September 2019

Published online: 28 October 2019

References

1. Integrative HMP. (iHMP) Research Network Consortium. The Integrative Human Microbiome Project. Nature. 2019:569:641-8.

2. Integrative HMP. (iHMP) Research Network Consortium. After the Integrative Human Microbiome Project, what's next for the microbiome community? Nature. 2019;569:599.

3. Proctor L. Priorities for the next 10 years of human microbiome research. Nature. 2019:569:623-5.

4. Douillard FP, de Vos WM. Biotechnology of health-promoting bacteria. Biotechnol Adv. 2019. https://doi.org/10.1016/j.biotechadv.2019.03.008.

5. Stenman LK, Burcelin R. Establishing a causal link between gut microbes, body weight gain and glucose metabolism in humans-towards treatment with probiotics. Benef Microbes. 2016; http://www.wageningenacademic. com/doi/abs/10.3920/BM2015.0069.

6. Brunkwall L, Orho-Melander M. The gut microbiome as a target for prevention and treatment of hyperglycaemia in type 2 diabetes: from current human evidence to future possibilities. Diabetologia. 2017. https:// doi.org/10.1007/s00125-017-4278-3.

7. Morotomi M, Nagai F, Watanabe Y. Description of Christensenella minuta gen. nov., sp. nov., isolated from human faeces, which forms a distinct branch in the order Clostridiales, and proposal of Christensenellaceae fam. nov. Int J Syst Evol Microbiol. 2011;62:144-9.

8. Lau SKP, McNabb A, Woo GKS, Hoang L, Fung AMY, Chung LMW, et al. Catabacter hongkongensis gen. nov., sp. nov., isolated from blood cultures of patients from Hong Kong and Canada. J Clin Microbiol. 2007;45:395-401.

9. Rajilić-Stojanović M, de Vos WM. The first 1000 cultured species of the human gastrointestinal microbiota. FEMS Microbiol Rev. 2014;38:996-1047.

10. Parte AC. LPSN - List of Prokaryotic names with Standing in Nomenclature (bacterio.net), 20 years on. Int J Syst Evol Microbiol. 2018:68:1825-9.

11. Parks DH, Chuvochina M, Waite DW, Rinke C, Skarshewski A, Chaumeil P-A, et al. A standardized bacterial taxonomy based on genome phylogeny substantially revises the tree of life. Nat Biotechnol. 2018;36:996-1004.

12. Alonso BL. Irigoyen von Sierakowski A, Sáez Nieto JA, Rosel AB. First report of human infection by Christensenella minuta, a Gram-negative, strickly anaerobic rod that inhabits the human intestine. Anaerobe. 2017:44:124-5.

13. Yang Y, Gu H, Sun Q, Wang J. Effects of Christensenella minuta lipopolysaccharide on RAW264.7 macrophages activation. Microb Pathog. 2018. https://doi.org/10.1016/j.micpath.2018.10.005

14. Rosa BA, Hallsworth-Pepin K, Martin J, Wollam A, Mitreva M. Genome sequence of Christensenella minuta DSM 22607T. Genome Announc. 2017; 5. https://doi.org/10.1128/genomeA.01451-16. 
15. Choi YJ, Won EJ, Kim SH, Shin MG, Shin JH, Suh SP. First case report of bacteremia due to Catabacter hongkongensis in a Korean patient. Ann Lab Med. 2017;37:84-7.

16. Lau SKP, Fan RYY, Lo H-W, Ng RHY, Wong SSY, Li IWS, et al. High mortality associated with Catabacter hongkongensis bacteremia. J Clin Microbiol. 2012;50:2239-43.

17. Elsendoorn A, Robert R, Culos A, Roblot F, Burucoa C. Catabacter hongkongensis Bacteremia with fatal septic shock. Emerg Infect Dis. 2011; 17:1330-1

18. Lau SKP, Teng JLL, Huang Y, Curreem SOT, Tsui SKW, Woo PCY. Draft genome sequence of Catabacter hongkongensis type strain HKU16T, isolated from a patient with bacteremia and intestinal obstruction. Genome Announc. 2015;3. https://doi.org/10.1128/genomeA.00531-15.

19. Ndongo S, Khelaifia S, Fournier P-E, Raoult D. Christensenella massiliensis, a new bacterial species isolated from the human gut; 2016. https://doi.org/10. 1016/j.nmni.2016.04.014.

20. Ndongo S, Dubourg G, Khelaifia S, Fournier PE, Raoult D. Christensenella timonensis, a new bacterial species isolated from the human gut. New Microbes New Infect. 2016;13:32-3.

21. Goodrich JK, Waters JL, Poole AC, Sutter JL, Koren O, Blekhman R, et al. Human genetics shape the gut microbiome. Cell. 2014;159. https://doi.org/ 10.1016/j.cell.2014.09.053.

22. Upadhyaya B, McCormack L, Fardin-Kia AR, Juenemann R, Nichenametla S, Clapper J, et al. Impact of dietary resistant starch type 4 on human gut microbiota and immunometabolic functions. Sci Rep. 2016;6:28797.

23. Hansen EE, Lozupone CA, Rey FE, Wu M, Guruge JL, Narra A, et al. Pangenome of the dominant human gut-associated archaeon, Methanobrevibacter smithii, studied in twins. Proc Natl Acad Sci U S A. 2011;108(Suppl 1):4599-606.

24. Bennett DC, Tun HM, Kim JE, Leung FC, Cheng KM. Characterization of cecal microbiota of the emu (Dromaius novaehollandiae). Vet Microbiol. 2013;166:304-10.

25. Crisol-Martínez E, Stanley D, Geier MS, Hughes RJ, Moore RJ. Sorghum and wheat differentially affect caecal microbiota and associated performance characteristics of meat chickens. PeerJ. 2017:5:e3071.

26. Wilkinson N, Hughes RJ, Aspden WJ, Chapman J, Moore RJ, Stanley D. The gastrointestinal tract microbiota of the Japanese quail. Coturnix japonica. Appl Microbiol Biotechnol. 2016;100:4201-9.

27. Videvall E, Song SJ, Bensch HM, Strandh M, Engelbrecht A, Serfontein N, et al. The development of gut microbiota in ostriches and its association with juvenile growth. bioRxiv. 2018:270017. https://doi.org/10.1101/270017.

28. Youngblut ND, Reischer GH, Walters W, Schuster N, Walzer C, Stalder G, et al. Host diet and evolutionary history explain different aspects of gut microbiome diversity among vertebrate clades. Nat Commun. 2019;10:2200.

29. Zhang J, Shi H, Wang Y, Li S, Cao Z, Ji S, et al. Effect of dietary forage to concentrate ratios on dynamic profile changes and interactions of ruminal microbiota and metabolites in Holstein heifers. Front Microbiol. 2017;8:2206.

30. Wang X, Martin GB, Wen Q, Liu S, Zhang J, Yu Y, et al. Linseed oil and heated linseed grain supplements have different effects on rumen bacterial community structures and fatty acid profiles in cashmere kids. J Anim Sci. 2019. https://doi.org/10.1093/jas/skz079.

31. Kamke J, Kittelmann S, Soni P, Li Y, Tavendale M, Ganesh S, et al. Rumen metagenome and metatranscriptome analyses of low methane yield sheep reveals a Sharpea-enriched microbiome characterised by lactic acid formation and utilisation. Microbiome. 2016;4:56.

32. He J, Yi L, Hai L, Ming L, Gao W, Ji R. Characterizing the bacterial microbiota in different gastrointestinal tract segments of the Bactrian camel. Sci Rep. 2018;8:654.

33. Samsudin AA, Evans PN, Wright A-DG, Al JR. Molecular diversity of the foregut bacteria community in the dromedary camel (Camelus dromedarius). Environ Microbiol. 2011;13:3024-35.

34. Li Z, Si H, Nan W, Wang X, Zhang T, Li G. Bacterial community and metabolome shifts in the cecum and colon of captive sika deer (Cervus nippon) from birth to post weaning. FEMS Microbiol Lett. 2019. https://doi. org/10.1093/femsle/fnz010.

35. Quan J, Cai G, Ye J, Yang M, Ding R, Wang X, et al. A global comparison of the microbiome compositions of three gut locations in commercial pigs with extreme feed conversion ratios. Sci Rep. 2018;8:4536

36. Lu C, Zhou J, Li Y, Zhang D, Wang Z, Li Y, et al. Structural modulation of gut microbiota in Bama minipigs in response to treatment with a "growthpromoting agent", salbutamol. Appl Microbiol Biotechnol. 2017. https://doi. org/10.1007/s00253-017-8329-y.
37. Gebreselassie EE, Jackson MI, Yerramilli M, Jewell DE. Anti-aging food that improves markers of health in senior dogs by modulating gut microbiota and metabolite profiles. bioRxiv. 2018:324327. https://doi.org/10.1101/324327.

38. Ramadan Z, Xu H, Laflamme D, Czarnecki-Maulden G, Li QJ, Labuda J, et al. Fecal microbiota of cats with naturally occurring chronic diarrhea assessed using 165 rRNA gene 454-pyrosequencing before and after dietary treatment. J Vet Intern Med. 2014;28:59-65.

39. Shiffman ME, Soo RM, Dennis PG, Morrison M, Tyson GW, Hugenholtz P. Gene and genome-centric analyses of koala and wombat fecal microbiomes point to metabolic specialization for Eucalyptus digestion. PeerJ. 2017;5:e4075.

40. Wang C, Zhu Y, Li F, Huang L. The effect of Lactobacillus isolates on growth performance, immune response, intestinal bacterial community composition of growing Rex Rabbits. J Anim Physiol Anim Nutr. 2017. https://doi.org/10. $1111 /$ jpn.12629.

41. Hansen NCK, Avershina E, Mydland LT, Næsset JA, Austbø D, Moen B, et al. High nutrient availability reduces the diversity and stability of the equine caecal microbiota. Microb Ecol Health Dis. 2015;26:27216.

42. McKenzie VJ, Song SJ, Delsuc F, Prest TL, Oliverio AM, Korpita TM, et al. The effects of captivity on the mammalian gut microbiome. Integr Comp Biol. 2017. https://doi.org/10.1093/icb/icx090.

43. Zhang X, Yasuda K, Gilmore RA, Westmoreland SV, Platt DM, Miller GM, et al. Alcohol-induced changes in the gut microbiome and metabolome of rhesus macaques. Psychopharmacology. 2019. https://doi.org/10.1007/ s00213-019-05217-z.

44. Yuan C, Graham M, Subramanian S. Microbiota-metabolites interactions in non-human primate gastrointestinal tract. bioRxiv. 2018:454496. https://doi. org/10.1101/454496

45. Allan N, Knotts TA, Pesapane R, Ramsey JJ, Castle S, Clifford D, et al. Conservation implications of shifting gut microbiomes in captive-reared endangered voles intended for reintroduction into the wild. Microorganisms. 2018;6. https://doi.org/10.3390/microorganisms6030094.

46. Connor KL, Chehoud C, Altrichter A, Chan L, DeSantis TZ, Lye SJ. Maternal metabolic, immune, and microbial systems in late pregnancy vary with malnutrition in mice. Biol Reprod. 2018;98:579-92.

47. Tillmann S, Abildgaard A, Winther G, Wegener G. Altered fecal microbiota composition in the Flinders sensitive line rat model of depression. Psychopharmacology. 2018. https://doi.org/10.1007/s00213-018-5094-2.

48. Tsukinowa E, Karita S, Asano S, Wakai Y, Oka Y, Furuta M, et al. Fecal microbiota of a dugong (Dugong dugong) in captivity at Toba Aquarium. J Gen Appl Microbiol. 2008:54:25-38.

49. Suzuki A, Ueda K, Segawa T, Suzuki M. Fecal microbiota of captive Antillean manatee Trichechus manatus manatus. FEMS Microbiol Lett. 2019. https:// doi.org/10.1093/femsle/fnz134

50. Baldo L, Riera JL, Mitsi K, Pretus JL. Processes shaping gut microbiota diversity in allopatric populations of the endemic lizard Podarcis lilfordi from Menorcan islets (Balearic Islands). FEMS Microbiol Ecol. 2018;94. https:// doi.org/10.1093/femsec/fix186.

51. Kohl KD, Brun A, Magallanes M, Brinkerhoff J, Laspiur A, Acosta JC, et al. Gut microbial ecology of lizards: insights into diversity in the wild, effects of captivity, variation across gut regions, and transmission. Mol Ecol. 2016. https://doi.org/10.1111/mec.13921.

52. Yuan ML, Dean SH, Longo AV, Rothermel BB, Tuberville TD, Zamudio KR. Kinship, inbreeding and fine-scale spatial structure influence gut microbiota in a hindgut-fermenting tortoise. Mol Ecol. 2015;24:2521-36.

53. Huang $\mathrm{S}$, Zhang $\mathrm{H}$. The impact of environmental heterogeneity and life stage on the hindgut microbiota of Holotrichia parallela larvae (Coleoptera: Scarabaeidae). PLoS One. 2013;8:e57169.

54. Ayayee PA, Keeney G, Sabree ZL, Muñoz-Garcia A. Compositional differences among female-associated and embryo-associated microbiota of the viviparous Pacific Beetle cockroach. Diploptera punctata. FEMS Microbiol Ecol. 2017;93. https://doi.org/10.1093/femsec/fix052.

55. Richards C, Otani S, Mikaelyan A, Poulsen M. Pycnoscelus surinamensis cockroach gut microbiota respond consistently to a fungal diet without mirroring those of fungus-farming termites. PLoS One. 2017:12:e0185745.

56. Zakrzewski M, Simms LA, Brown A, Appleyard M, Irwin J, Waddell N, et al. IL23R-protective coding variant promotes beneficial bacteria and diversity in the ileal microbiome in healthy individuals without inflammatory bowel disease. J Crohns Colitis. 2018. https://doi.org/10.1093/ecco-jcc/jiy188.

57. Huang YJ, Kim E, Cox MJ, Brodie EL, Brown R, Wiener-Kronish JP, et al. A persistent and diverse airway microbiota present during chronic obstructive pulmonary disease exacerbations. OMICS. 2010;14:9-59. 
58. Burns MB, Montassier E, Abrahante J, Priya S, Niccum DE, Khoruts A, et al. Colorectal cancer mutational profiles correlate with defined microbial communities in the tumor microenvironment. PLoS Genet. 2018;14:e1007376.

59. Moreno-Indias I, Sánchez-Alcoholado L, García-Fuentes E, Cardona F, Queipo-Ortuno MI, Tinahones FJ. Insulin resistance is associated with specific gut microbiota in appendix samples from morbidly obese patients. Am J Transl Res. 2016;8:5672-84.

60. Brooks AW, Priya S, Blekhman R, Bordenstein SR. Gut microbiota diversity across ethnicities in the United States. PLoS Biol. 2018;16:e2006842.

61. Turnbaugh PJ, Hamady M, Yatsunenko T, Cantarel BL, Duncan A, Ley RE, et al. A core gut microbiome in obese and lean twins. Nature. 2009;457:480-4

62. Turpin W, Espin-Garcia O, Xu W, Silverberg MS, Kevans D, Smith Ml, et al. Association of host genome with intestinal microbial composition in a large healthy cohort. Nat Genet. 2016:48:1413-7.

63. Obregon-Tito AJ, Tito RY, Metcalf J, Sankaranarayanan K, Clemente JC, Ursell $L K$, et al. Subsistence strategies in traditional societies distinguish gut microbiomes. Nat Commun. 2015;6:6505.

64. Escobar JS, Klotz B, Valdes BE, Agudelo GM. The gut microbiota of Colombians differs from that of Americans, Europeans and Asians. BMC Microbiol. 2014;14:311.

65. Org E, Blum Y, Kasela S, Mehrabian M, Kuusisto J, Kangas AJ, et al. Relationships between gut microbiota, plasma metabolites, and metabolic syndrome traits in the METSIM cohort. Genome Biol. 2017;18:70.

66. Lim MY, You HJ, Yoon HS, Kwon B, Lee JY, Lee S, et al. The effect of heritability and host genetics on the gut microbiota and metabolic syndrome. Gut. 2016. https://doi.org/10.1136/gutjnl-2015-311326.

67. Oki K, Toyama M, Banno T, Chonan O, Benno Y, Watanabe K. Comprehensive analysis of the fecal microbiota of healthy Japanese adults reveals a new bacterial lineage associated with a phenotype characterized by a high frequency of bowel movements and a lean body type. BMC Microbiol. 2016;16:284.

68. Ayeni FA, Biagi E, Rampelli S, Fiori J, Soverini M, Audu HJ, et al. Infant and adult gut microbiome and metabolome in rural Bassa and urban settlers from Nigeria. Cell Rep. 2018;23:3056-67.

69. Gomez A, Petrzelkova KJ, Burns MB, Yeoman CJ, Amato KR, Vlckova K, et al. Gut microbiome of coexisting BaAka Pygmies and Bantu reflects gradients of traditional subsistence patterns. Cell Rep. 2016;14:2142-53.

70. Morton ER, Lynch J, Froment A, Lafosse S, Heyer E, Przeworski M, et al. Variation in rural African gut microbiota is strongly correlated with colonization by Entamoeba and Subsistence. PLoS Genet. 2015;11:e1005658.

71. Barrett HL, Gomez-Arango LF, Wilkinson SA, Mclntyre HD, Callaway LK, Morrison $\mathrm{M}$, et al. A vegetarian diet is a major determinant of gut microbiota composition in early pregnancy. Nutrients. 2018;10. https://doi. org/10.3390/nu10070890.

72. Deschasaux M, Bouter KE, Prodan A, Levin E, Groen AK, Herrema H, et al. Depicting the composition of gut microbiota in a population with varied ethnic origins but shared geography. Nat Med. 2018. https://doi.org/10. 1038/s41591-018-0160-1.

73. Chi L, Mahbub R, Gao B, Bian X, Tu P, Ru H, et al. Nicotine alters the gut microbiome and metabolites of gut-brain interactions in a sex-specific manner. Chem Res Toxicol. 2017;30:2110-9.

74. Davis DJ, Hecht PM, Jasarevic E, Beversdorf DQ, Will MJ, Fritsche K, et al. Sex-specific effects of docosahexaenoic acid (DHA) on the microbiome and behavior of socially-isolated mice. Brain Behav Immun. 2016. https://doi.org/ 10.1016/j.bbi.2016.09.003.

75. Kong F, Hua Y, Zeng B, Ning R, Li Y, Zhao J. Gut microbiota signatures of longevity. Curr Biol. 2016;26:R832-3.

76. Wang F, Yu T, Huang G, Cai D, Liang X, Su H, et al. Gut microbiota community and its assembly associated with age and diet in Chinese centenarians. J Microbiol Biotechnol. 2015;25:1195-204.

77. Biagi E, Franceschi C, Rampelli S, Severgnini M, Ostan R, Turroni S, et al. Gut microbiota and extreme longevity. Curr Biol. 2016. https://doi.org/10.1016/j. cub.2016.04.016.

78. Kim B-S, Choi CW, Shin H, Jin S-P, Bae J-S, Han M, et al. Comparison of the gut microbiota of centenarians in longevity villages of South Korea with those of other age groups. J Microbiol Biotechnol. 2019. https://doi.org/10.4014/jmb.1811.11023.

79. Anand R, Song Y, Garg S, Girotra M, Sinha A, Sivaraman A, et al. Effect of aging on the composition of fecal microbiota in donors for FMT and its impact on clinical outcomes. Dig Dis Sci. 2017. https:/doi.org/10.1007/s10620-017-4449-6.

80. Estaki M, Pither J, Baumeister P, Little JP, Gill SK, Ghosh S, et al. Cardiorespiratory fitness as a predictor of intestinal microbial diversity and distinct metagenomic functions. Microbiome. 2016;4:42.
81. Jackson MA, Bonder MJ, Kuncheva Z, Zierer J, Fu J, Kurilshikov A, et al. Detection of stable community structures within gut microbiota cooccurrence networks from different human populations. PeerJ. 2018;6: e4303.

82. Shin J-H, Park YH, Sim M, Kim S-A, Joung H, Shin D-M. Serum level of sex steroid hormone is associated with diversity and profiles of human gut microbiome. Res Microbiol. 2019. https://doi.org/10.1016/j.resmic.2019.03.003.

83. Goodrich JK, Davenport ER, Beaumont M, Jackson MA, Knight R, Ober C, et al. Genetic Determinants of the Gut Microbiome in UK Twins. Cell Host Microbe. 2016;19:731-43.

84. Beaumont M, Goodrich JK, Jackson MA, Yet I, Davenport ER, Vieira-Silva S, et al. Heritable components of the human fecal microbiome are associated with visceral fat. Genome Biol. 2016;17:189.

85. Xie H, Guo R, Zhong H, Feng Q, Lan Z, Qin B, et al. Shotgun metagenomics of 250 adult twins reveals genetic and environmental impacts on the gut microbiome. Cell Syst. 2016. https://doi.org/10.1016/j.cels.2016.10.004.

86. Yatsunenko T, Rey FE, Manary MJ, Trehan I, Dominguez-Bello MG, Contreras $\mathrm{M}$, et al. Human gut microbiome viewed across age and geography. Nature. 2012;486:222-7.

87. Goodrich JK, Davenport ER, Waters JL, Clark AG, Ley RE. Cross-species comparisons of host genetic associations with the microbiome. Science. 2016;352:532-5.

88. Wacklin P, Tuimala J, Nikkilä J, Tims S, Mäkivuokko H, Alakulppi N, et al. Faecal microbiota composition in adults is associated with the FUT2 gene determining the secretor status. PLoS One. 2014;9:e94863.

89. Davenport ER, Goodrich JK, Bell JT, Spector TD, Ley RE, Clark AG. ABO antigen and secretor statuses are not associated with gut microbiota composition in 1,500 twins. BMC Genomics. 2016;17:941.

90. Turpin W, Bedrani L, Espin-Garcia O, Xu W, Silverberg MS, Smith Ml, et al. FUT2 genotype and secretory status are not associated with fecal microbial composition and inferred function in healthy subjects. Gut Microbes. 2018;9:357-68.

91. Le Gall G, Guttula K, Kellingray L, Tett AJ, Ten Hoopen R, Kemsley KE, et al. Metabolite quantification of faecal extracts from colorectal cancer patients and healthy controls. Oncotarget. 2018;9:33278-89.

92. Yazici C, Wolf PG, Kim H, Cross T-WL, Vermillion K, Carroll T, et al. Racedependent association of sulfidogenic bacteria with colorectal cancer. Gut. 2017. https://doi.org/10.1136/gutjnl-2016-313321.

93. Peters BA, Shapiro JA, Church TR, Miller G, Trinh-Shevrin C, Yuen E, et al. A taxonomic signature of obesity in a large study of American adults. Sci Rep. 2018:8:9749

94. López-Contreras BE, Morán-Ramos S, Villarruel-Vázquez R, Macías-Kauffer L, Villamil-Ramírez H, León-Mimila P, et al. Composition of gut microbiota in obese and normal-weight Mexican school-age children and its association with metabolic traits. Pediatr Obes. 2018;13:381-8.

95. Ferrer M, Ruiz A, Lanza F, Haange S-B, Oberbach A, Till H, et al. Microbiota from the distal guts of lean and obese adolescents exhibit partial functional redundancy besides clear differences in community structure. Environ Microbiol. 2013;15:211-26.

96. Fu J, Bonder MJ, Cenit MC, Tigchelaar EF, Maatman A, Dekens JAM, et al. The gut microbiome contributes to a substantial proportion of the variation in blood lipids. Circ Res. 2015;117:817-24.

97. Kummen M, Holm K, Anmarkrud JA, Nygård S, Vesterhus M, Høivik ML, et al. The gut microbial profile in patients with primary sclerosing cholangitis is distinct from patients with ulcerative colitis without biliary disease and healthy controls. Gut. 2016. https://doi.org/10.1136/gutjnl-2015-310500.

98. Stanislawski MA, Dabelea D, Wagner BD, Sontag MK, Lozupone CA, Eggesbø M. Pre-pregnancy weight, gestational weight gain, and the gut microbiota of mothers and their infants. Microbiome. 2017;5:113.

99. Yun Y, Kim H-N, Kim SE, Heo SG, Chang Y, Ryu S, et al. Comparative analysis of gut microbiota associated with body mass index in a large Korean cohort. BMC Microbiol. 2017;17:151.

100. Alemán JO, Bokulich NA, Swann JR, Walker JM, De Rosa JC, Battaglia T, et al. Fecal microbiota and bile acid interactions with systemic and adipose tissue metabolism in diet-induced weight loss of obese postmenopausal women. J Transl Med. 2018;16:244.

101. Walters WA, Xu Z, Knight R. Meta-analyses of human gut microbes associated with obesity and IBD. FEBS Lett. 2014;588:4223-33.

102. Hibberd AA, Yde CC, Ziegler ML, Honoré AH, Saarinen MT, Lahtinen S, et al. Probiotic or synbiotic alters the gut microbiota and metabolism in a randomised controlled trial of weight management in overweight adults. Benef Microbes. 2019;10(2):121-35. 
103. Guzman-Castaneda SJ, Ortega-Vega EL, de la Cuesta-Zuluaga J, VelasquezMejia EP, Rojas W, Bedoya G, et al. Gut microbiota composition explains more variance in the host cardiometabolic risk than genetic ancestry. bioRxiv. 2018:394726. https://doi.org/10.1101/394726.

104. He Y, Wu W, Wu S, Zheng H-M, Li P, Sheng H-F, et al. Linking gut microbiota, metabolic syndrome and economic status based on a population-level analysis. Microbiome. 2018;6:172.

105. Gomez-Arango LF, Barrett HL, McIntyre HD, Callaway LK, Morrison M, Dekker Nitert $M$, et al. Increased systolic and diastolic blood pressure is associated with altered gut microbiota composition and butyrate production in early pregnancy. Hypertension. 2016;68:974-81.

106. Yanai H, Tomono $Y$, Ito K, Furutani N, Yoshida H, Tada N. The underlying mechanisms for development of hypertension in the metabolic syndrome Nutr J. 2008;7:10.

107. Lippert K, Kedenko L, Antonielli L, Kedenko I, Gemeier C, Leitner M, et al. Gut microbiota dysbiosis associated with glucose metabolism disorders and the metabolic syndrome in older adults. Benef Microbes. 2017;8(4):545-56.

108. Bowyer RCE, Jackson MA, Pallister T, Skinner J, Spector TD, Welch AA, et al. Use of dietary indices to control for diet in human gut microbiota studies. Microbiome. 2018;6:77.

109. Maskarinec G, Hullar MAJ, Monroe KR, Shepherd JA, Hunt J, Randolph TW, et al. Fecal microbial diversity and structure are associated with diet quality in the multiethnic cohort adiposity phenotype study. J Nutr. 2019. https:// doi.org/10.1093/jn/nxz065.

110. Klimenko NS, Tyakht AV, Popenko AS, Vasiliev AS, Altukhov IA, Ischenko DS, et al. Microbiome responses to an uncontrolled short-term diet intervention in the frame of the citizen science project. Nutrients. 2018;10. https://doi. org/10.3390/nu10050576

111. De Filippis F, Pellegrini N, Vannini L, Jeffery IB, La Storia A, Laghi L, et al. High-level adherence to a Mediterranean diet beneficially impacts the gut microbiota and associated metabolome. Gut. 2016;65:1812-21.

112. Azcarate-Peril MA, Ritter AJ, Savaiano D, Monteagudo-Mera A, Anderson C, Magness ST, et al. Impact of short-chain galactooligosaccharides on the gut microbiome of lactose-intolerant individuals. Proc Natl Acad Sci U S A. 2017. https://doi.org/10.1073/pnas.1606722113.

113. David LA, Maurice CF, Carmody RN, Gootenberg DB, Button JE, Wolfe BE, et al. Diet rapidly and reproducibly alters the human gut microbiome. Nature. 2014;505:559-63.

114. Roager HM, Hansen LBS, Bahl MI, Frandsen HL, Carvalho V, Gøbel RJ, et al. Colonic transit time is related to bacterial metabolism and mucosal turnover in the gut. Nat Microbiol. 2016;1:16093.

115. Beaumont M, Portune KJ, Steuer N, Lan A, Cerrudo V, Audebert M, et al. Quantity and source of dietary protein influence metabolite production by gut microbiota and rectal mucosa gene expression: a randomized, parallel, double-blind trial in overweight humans. Am J Clin Nutr. 2017;106:1005-19.

116. Manor O, Zubair N, Conomos MP, Xu X, Rohwer JE, Krafft CE, et al. A multiomic association study of trimethylamine N-oxide. Cell Rep. 2018;24:935-46.

117. Jiminez JA, Uwiera TC, Abbott DW, Uwiera RRE, Inglis GD. Impacts of resistant starch and wheat bran consumption on enteric inflammation in relation to colonic bacterial community structures and short-chain fatty acid concentrations in mice. Gut Pathog. 2016;8:67.

118. Zheng J, Cheng G, Li Q, Jiao S, Feng C, Zhao X, et al. Chitin oligosaccharide modulates gut microbiota and attenuates high-fat-diet-induced metabolic syndrome in mice. Mar Drugs. 2018;16. https://doi.org/10.3390/md16020066.

119. Ferrario C, Statello R, Carnevali L, Mancabelli L, Milani C, Mangifesta M, et al. How to feed the mammalian gut microbiota: bacterial and metabolic modulation by dietary fibers. Front Microbiol. 2017:8:1749.

120. Mancabelli L, Milani C, Lugli GA, Turroni F, Cocconi D, van Sinderen D, et al. Identification of universal gut microbial biomarkers of common human intestinal diseases by meta-analysis. FEMS Microbiol Ecol. 2017. https://doi. org/10.1093/femsec/fix153.

121. Gevers D, Kugathasan S, Denson LA, Vázquez-Baeza Y, Van Treuren W, Ren $B$, et al. The treatment-naive microbiome in new-onset Crohn's disease. Cell Host Microbe. 2014;15:382-92.

122. Imhann F, Vich Vila A, Bonder MJ, Fu J, Gevers D, Visschedijk MC, et al. Interplay of host genetics and gut microbiota underlying the onset and clinical presentation of inflammatory bowel disease. Gut. 2016. https://doi. org/10.1136/gutjnl-2016-312135.

123. Palm NW, de Zoete MR, Cullen TW, Barry NA, Stefanowski J, Hao L, et al. Immunoglobulin A coating identifies colitogenic bacteria in inflammatory bowel disease. Cell. 2014;158:1000-10.
124. Pascal V, Pozuelo M, Borruel N, Casellas F, Campos D, Santiago A, et al. A microbial signature for Crohn's disease. Gut. 2017. https://doi.org/10.1136/ gutjnl-2016-313235.

125. Lee T, Clavel T, Smirnov K, Schmidt A, Lagkouvardos I, Walker A, et al. Oral versus intravenous iron replacement therapy distinctly alters the gut microbiota and metabolome in patients with IBD. Gut. 2017;66:863-71.

126. Wright EK, Kamm MA, Wagner J, Teo S-M, Cruz PD, Hamilton AL, et al. Microbial factors associated with postoperative Crohn's disease recurrence. J Crohns Colitis. 2017;11:191-203.

127. Kennedy NA, Lamb CA, Berry SH, Walker AW, Mansfield J, Parkes M, et al. The impact of NOD2 variants on fecal microbiota in Crohn's disease and controls without gastrointestinal disease. Inflamm Bowel Dis. 2018;24:583-92.

128. Pérez-Brocal V, García-López R, Nos P, Beltrán B, Moret I, Moya A. Metagenomic analysis of Crohn's disease patients identifies changes in the virome and microbiome related to disease status and therapy, and detects potential interactions and biomarkers. Inflamm Bowel Dis. 2015;21:2515-32.

129. Papa E, Docktor M, Smillie C, Weber S, Preheim SP, Gevers D, et al. Noninvasive mapping of the gastrointestinal microbiota identifies children with inflammatory bowel disease. PLoS One. 2012;7:e39242.

130. Rajilic-Stojanovic M, Shanahan F, Guarner F, de Vos WM. Phylogenetic analysis of dysbiosis in ulcerative colitis during remission. Inflamm Bowel Dis. 2013;19:481.

131. Jalanka-Tuovinen J, Salojärvi J, Salonen A, Immonen O, Garsed K, Kelly FM, et al. Faecal microbiota composition and host-microbe cross-talk following gastroenteritis and in postinfectious irritable bowel syndrome. Gut. 2014;63: $1737-45$.

132. De Palma G, Lynch MDJ, Lu J, Dang VT, Deng Y, Jury J, et al. Transplantation of fecal microbiota from patients with irritable bowel syndrome alters gut function and behavior in recipient mice. Sci Transl Med. 2017;9. https://doi. org/10.1126/scitranslmed.aaf6397.

133. Pozuelo M, Panda S, Santiago A, Mendez S, Accarino A, Santos J, et al. Reduction of butyrate- and methane-producing microorganisms in patients with irritable bowel syndrome. Sci Rep. 2015:5:12693.

134. Hollister EB, Cain KC, Shulman RJ, Jarrett ME, Burr RL, Ko C, et al. Relationships of microbiome markers with extraintestinal, psychological distress and gastrointestinal symptoms, and quality of life in women with irritable bowel syndrome. J Clin Gastroenterol. 2018. https://doi.org/10.1097/ MCG.0000000000001107.

135. Tigchelaar EF, Bonder MJ, Jankipersadsing SA, Fu J, Wijmenga C, Zhernakova A. Gut microbiota composition associated with stool consistency. Gut. 2015; 65. https://doi.org/10.1136/gutjnl-2015-310328.

136. Jalanka J, Major G, Murray K, Singh G, Nowak A, Kurtz C, et al. The effect of Psyllium husk on intestinal microbiota in constipated patients and healthy controls. Int J Mol Sci. 2019;20. https://doi.org/10.3390/ijms20020433.

137. Pedrosa Carrasco AJ, Timmermann L, Pedrosa DJ. Management of constipation in patients with Parkinson's disease. NPJ Parkinsons Dis. 2018:4:6.

138. Wiesel PH, Norton C, Glickman S, Kamm MA. Pathophysiology and management of bowel dysfunction in multiple sclerosis. Eur J Gastroenterol Hepatol. 2001;13:441-8.

139. Barichella M, Severgnini M, Cilia R, Cassani E, Bolliri C, Caronni S, et al. Unraveling gut microbiota in Parkinson's disease and atypical parkinsonism. Mov Disord. 2018. https://doi.org/10.1002/mds.27581.

140. Hill-Burns EM, Debelius JW, Morton JT, Wissemann WT, Lewis MR, Wallen ZD, et al. Parkinson's disease and Parkinson's disease medications have distinct signatures of the gut microbiome. Mov Disord. 2017. https://doi. org/10.1002/mds.26942.

141. Petrov VA, Saltykova IV, Zhukova IA, Alifirova VM, Zhukova NG, Dorofeeva $\mathrm{YB}$, et al. Analysis of gut microbiota in patients with Parkinson's disease. Bull Exp Biol Med. 2017. https://doi.org/10.1007/s10517-017-3700-7.

142. Tremlett H, Fadrosh DW, Faruqi AA, Zhu F, Hart J, Roalstad S, et al. Gut microbiota in early pediatric multiple sclerosis: a case-control study. Eur J Neurol. 2016;23:1308-21.

143. Chang C-J, Lin T-L, Tsai Y-L, Wu T-R, Lai W-F, Lu C-C, et al. Next generation probiotics in disease amelioration. J Food Drug Anal. 2019. https://doi.org/ 10.1016/j.jfda.2018.12.011.

\section{Publisher's Note}

Springer Nature remains neutral with regard to jurisdictional claims in published maps and institutional affiliations. 